\title{
Changes to the Monitoring Trends in Burn Severity program mapping production procedures and data products
}

\author{
Joshua J. Picotte ${ }^{1 *} \mathbb{D}$, Krishna Bhattarai ${ }^{2}$, Danny Howard ${ }^{2}$, Jennifer Lecker ${ }^{3}$, Justin Epting ${ }^{4}$, Brad Quayle ${ }^{4}$,
} Nate Benson ${ }^{5}$ and Kurtis Nelson ${ }^{6}$

\begin{abstract}
Background: The Monitoring Trends in Burn Severity (MTBS) program has been providing the fire science community with large fire perimeter and burn severity data for the past 14 years. As of October 2019, 22969 fires have been mapped by the MTBS program and are available on the MTBS website (https://www.mtbs.gov). These data have been widely used by researchers to examine a variety of fire and climate science topics. However, MTBS has undergone significant changes to its fire mapping methodology, the remotely sensed imagery used to map fires, and the subsequent fire occurrence, burned boundary, and severity databases. To gather a better understanding of these changes and the potential impacts that they may have on the user community, we examined the changes to the MTBS burn mapping protocols and whether remapped burned area boundary and severity products differ significantly from the original MTBS products.

Results: As MTBS data have been used over the course of many years and for many disparate applications, users should be aware that the MTBS burned area and severity products have been actively reviewed and revised to benefit from more robust satellite image availability and to address any observed quality issues. In a sample of 123 remapped fires, we found no significant change in the burned area boundary products when compared to the original mapped fires; however, significant changes did exist in the distribution of unburned, low, and moderate burn severity pixels within the thematic product.

Conclusions: Analysis of these remapped fires provides a look into how the MTBS fire mapping methods have evolved over time. In the future, additional changes to the MTBS data record may impact data users' downstream applications. The MTBS program has an established continuous improvement approach to the MTBS methodology and products, and subsequently encourages users to confirm that they are using the most recent data.
\end{abstract}

Keywords: burned area boundaries, burn severity, fire, geospatial data, remap, remote sensing

\footnotetext{
* Correspondence: jpicotte@contractor.usgs.gov

'ASRC Federal Data Solutions, Contractor to the US Geological Survey, Earth Resources Observation and Science Center, 47914 252nd Street, Sioux Falls, South Dakota 57198, USA

Full list of author information is available at the end of the article
}

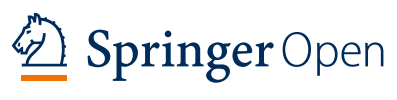

(c) The Author(s). 2020 Open Access This article is licensed under a Creative Commons Attribution 4.0 International License which permits use, sharing, adaptation, distribution and reproduction in any medium or format, as long as you give appropriate credit to the original author(s) and the source, provide a link to the Creative Commons licence, and indicate if changes were made. The images or other third party material in this article are included in the article's Creative Commons licence, unless indicated otherwise in a credit line to the material. If material is not included in the article's Creative Commons licence and your intended use is not permitted by statutory regulation or exceeds the permitted use, you will need to obtain permission directly from the copyright holder. To view a copy of this licence, visit http://creativecommons.org/licenses/by/4.0/. 


\section{Resumen}

Antecedentes: El programa de Monitoreo de Tendencias de Severidad de Fuego (MTBS) ha venido proveyendo a la comunidad de investigadores en fuegos con datos de perímetros y severidad de incendios en los últimos 14 años. Hasta octubre de 2019, 22.969 incendios han sido mapeados por el programa MTBS y están disponibles en el sitio web (https://www.mtbs.gov). Estos datos han sido ampliamente usados por investigadores para examinar una variedad de tópicos científicos en fuego y clima. Sin embargo, MTBS ha experimentado cambios significativos en su metodología de mapeo de fuegos, en las imágenes de sensores remotos usadas para mapear fuegos, y subsecuentemente en la ocurrencia, perímetros y bases de datos sobre severidad de fuegos. Para lograr un mejor entendimiento de esos cambios y el impacto potencial que podrían tener en la comunidad de usuarios, examinamos los cambios en los protocolos de mapeo del MTBS y si el el re- mapeo de los productos, como el límite del área quemada y su severidad, difieren significativamente de los mapeados con los productos MTBS originales.

Resultados: Como los datos de MTBS han sido usados por muchos años para muy diferentes aplicaciones, los usuarios deben estar alertas de que los productos MTBS para determinar área y severidad han sido revisados y re examinados activamente para beneficiarse de la disponibilidad de imágenes satelitales más robustas y para abordar cualquier cuestión relacionada con su calidad. En un ejemplo de 123 incendios re-mapeados, encontramos que no había cambios significativos cuando se comparaban con los mapas originales; desde luego, hubo cambios en la distribución de pixeles de áreas no quemadas, y de áreas quemadas a baja y mediana severidad dentro del producto temático.

Conclusiones: El análisis de estos incendios re-mapeados proveyeron de un pantallazo sobre cómo los métodos de re mapeo han evolucionado en el tiempo. En el futuro, cambios adicionales a los datos de registros de MTBS pueden impactar en la aplicación y uso posterior de estos datos. El programa MTBS tiene un enfoque de mejoramiento continuo de su metodología y productos, y subsecuentemente induce a los usuarios a confirmar de que están usando los datos más recientes.

\section{Abbreviations}

CBI: $\quad$ Composite Burn Index

CONUS: CONterminous US

ETD: $\quad$ Event Tracking Database

ETM+: $\quad$ Landsat Enhanced Thematic Mapper Plus

FOD: $\quad$ Fire Occurrence Database

FPA: $\quad$ Fire Program Analysis

IRWIN: Integrated Reporting of Wild-fire INformation

MSI: $\quad$ Sentinel 2 MultiSpectral Instrument

MTBS: $\quad$ Monitoring Trends in Burn Severity

TM: $\quad$ Landsat Thematic Mapper

\section{Introduction}

The Monitoring Trends in Burn Severity (MTBS) program was established in 2006, with a mission to remotely assess the location, extent, burned area boundaries, and burn severity (see Fig. 1 for an example) of large fires using Landsat imagery on all lands across the conterminous United States (CONUS), and Alaska, Hawaii, and Puerto Rico, USA, for the period from 1984 to present (Eidenshink et al. 2007). This includes all fires $\geq 405$ hectares in the western United States, Alaska, and Hawaii. In addition, the program maps and assesses fires $\geq 202$ hectares in the eastern United States and Puerto Rico.
The MTBS program originally defined burn severity as visible alteration of vegetation, dead biomass, and soil that occurs within a fire perimeter (Eidenshink et al. 2007). These changes can be assessed on the ground (e.g., via the Composite Burn Index, CBI) and subsequently related to remotely sensed (e.g., via the differenced Normalized Burn Ratio, dNBR) estimates of burn severity (Eidenshink et al. 2007; see Fig. 1 for an example comparison between CBI and dNBR). CBI assesses damage to vegetated and dead biomass using a continuous index with values ranging from 0.0 to 3.0, while dNBR has been used to assess the changes in reflection in vegetated and nonvegetated surfaces resulting from fire (Key and Benson 2006). The dNBR metric is a measure of the difference between a pre- and post-fire NBR image, with typical values ranging between -2000 and 2000 . Initial regression relationships between $\mathrm{CBI}$ and $\mathrm{dNBR}$ informed the MTBS program (Eidenshink et al. 2007), and subsequent investigations suggest that $\mathrm{dNBR}$ or a variant (e.g., Relativized dNBR [RdNBR] or Relativized Burn Ratio) can be used as a viable estimate of burn severity within some ecosystems in the United States ( Zhu et al. 2006; Picotte and Robertson 2011b; Cansler and McKenzie 2012; Parks et al. 2019).

Data produced by MTBS, including burn perimeters and severity products (https://www.mtbs.gov), have become increasingly critical in fire-related research in the United States. For example, MTBS data have been used 


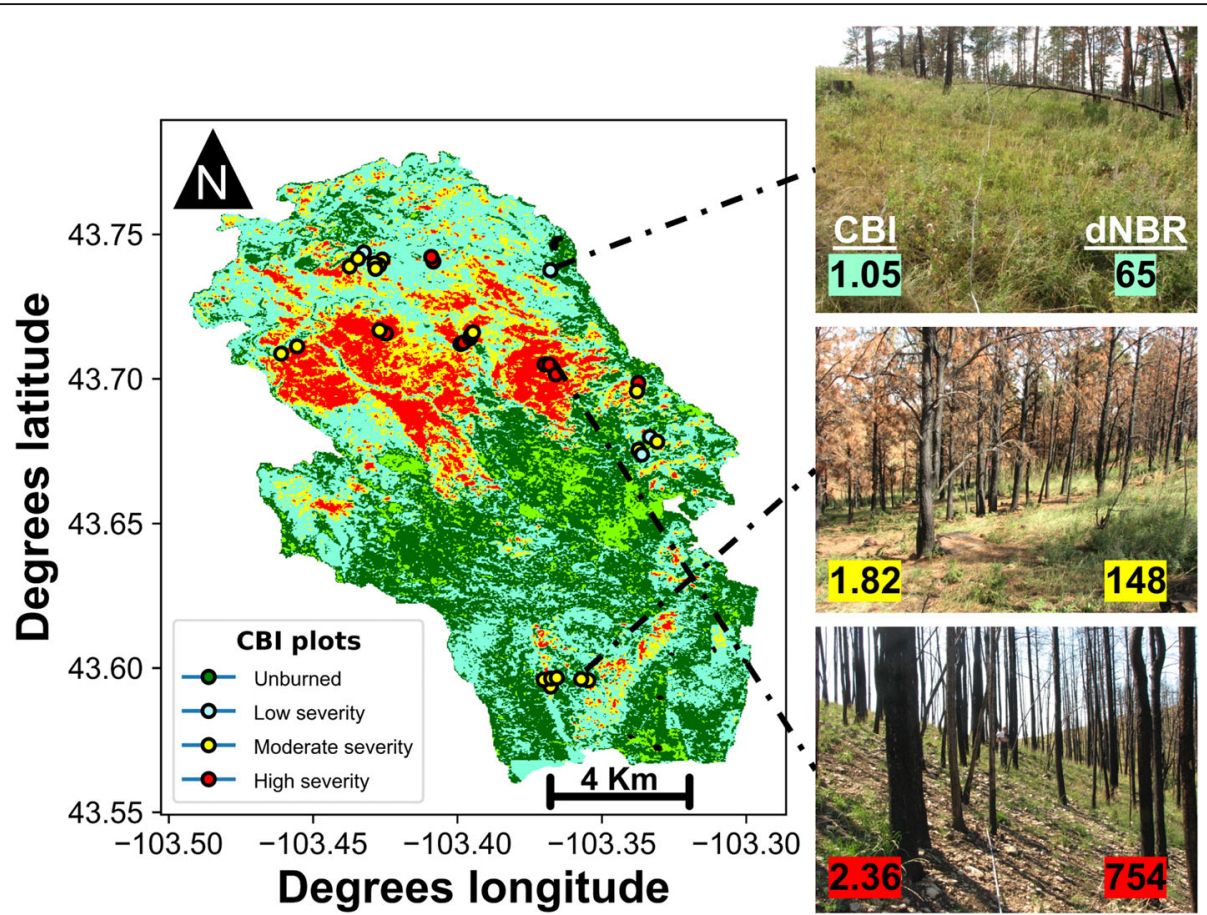

Fig. 1 Monitoring Trends in Burn Severity (MTBS) burn severity assessment image and Composite Burn Severity (CBI) plot locations for the 11 December 2017, Legion Lake Fire (near Custer, South Dakota, USA). Associated CBI plot photos, CBI values, and differenced Normalized Burn Ratio (dNBR) values are provided to visually illustrate on the ground CBI versus remotely assessed dNBR values of burn severity

in assessing trends in burned area extent (Finco et al. 2012; Dennison et al. 2014; Zhao et al. 2015; Picotte et al. 2016), burn severity (Zhao et al. 2015; Picotte et al. 2016), wildfire emissions (Urbanski et al. 2011; French et al. 2014), wildfire exposure and risk (Radeloff et al. 2018), and the effects of fuel reduction (Meigs et al. 2016). Although the MTBS mapping protocols outlined in Eidenshink et al. (2007) are largely still applied, some of the protocols have changed. Most importantly, the Landsat image archive becoming publicly and freely available in 2008 removed a major cost constraint, enabling the MTBS program to expand its scope and map many more fires.

\section{Protocol evolution}

\section{Fire Occurrence Database}

Current and historical fire records were initially compiled from Federal fire reporting databases, including the Incident Command System database and available state fire reporting databases, as part of the original data request for the MTBS Fire Occurrence Database (FOD). Inclusion of prescribed fires as part of the scope of MTBS resulted in a large availability of fire occurrence data that included both wildland fire and prescribed fire incident types. Because of the volume of fires, the lack of availability of prescribed fire records for all states, and the need for consistency in the MTBS data record, the decision was made in 2014 to no longer consider stateprescribed fire records for assessment. This decision impacted the mapping of fires in Florida, USA, which accounted for approximately $20 \%$ of mapped fires before 2013 and 9\% afterwards (https://mtbs.gov/viewer/index. html, accessed 5 August 2019).

Other major changes that occurred in 2014 included the transition of fire occurrence tracking and mapping information into a relational database management system (MTBS internally used Event Tracking Database, ETD) and the change to a more automated system for compiling fire occurrence records. The large number of fire records assessed and mapped by MTBS resulted in the need for the development of an expanded ETD to also track mapping parameters, metadata, and all mapped fire occurrence information. Fire identifications (IDs) based on the new system were generated for current and historical fire records and were inserted into the ETD. Each fire record is uniquely established to intuitively identify the US state where the fire is located, the specific geographic location of the fire origin, and the date of fire ignition. Fire information (i.e., fire name, geographic coordinates for the location of ignition, size, ignition date, containment date, etc.) and input data, output products, processing and analysis parameters, and other metadata information collected for each mapped fire were uploaded into the ETD. 
During the same timeframe as the ETD development, Short (2014) developed the Fire Program Analysis (FPA) FOD that included federal and nonfederal fires from 1992 to 2011, which was subsequently expanded to include 2012 and 2013 (Short 2015). The FPA FOD was subsequently replaced by the Integrated Reporting of Wild-Fire Information (IRWIN; (https://www.forestsandrangelands.gov/WFIT/ applications/IRWIN/background.shtml, accessed 5 August 2019) tool to collect and report fire event data with a unique identification for both federal and non-federal data. IRWIN was designed to ingest data from multiple, disparate fire reporting systems of record with automated capabilities to eliminate redundant records. Consequently, MTBS adopted IRWIN in 2014 as its primary source of fire records for ingest into the ETD. Once ingested into the ETD, each IRWIN record receives its own unique MTBS fire ID and is targeted for assessment and potential mapping by the MTBS program.

\section{Landsat image considerations}

The long history of the Landsat $30 \mathrm{~m}$ products (1984 to present), including the Thematic Mapper (TM), Enhanced Thematic Mapper Plus (ETM+), and Operational Land Imager, provided the MTBS program with a continuous source of data. Throughout the lifetime of the MTBS program, the Normalized Burn Ratio (NBR; García and Caselles 1991; Key and Benson 2006) index, calculated with the near-infrared and shortwave-infrared Landsat bands, has been used because of its sensitivity to identify spectral variation in burn severity. During the first year of the MTBS program, the dNBR was the only remotely sensed change detection product that was produced. To create the thematic burn severity product from dNBR, MTBS analysts visually interpreted the burn severity thresholds and compared these thresholds to outputs from techniques developed by Key and Benson (2006) that were originally developed and applied within Glacier National Park (Montana, USA) and further validated within CONUS and Alaska (Zhu et al. 2006). The thresholding process is therefore largely subjective, but see Fig. 1 for an example of an MTBS thematic image compared to ground-validated CBI plots and dNBR values. The MTBS program extended this methodology for use in biophysical settings throughout the United States.

The MTBS program continued to solely use dNBR for mapping burn severity until the development of the Relativized dNBR by Miller and Thode (2007). The two indices are fundamentally different: $\mathrm{dNBR}$ is an estimate of the absolute magnitude of change to vegetation and soil strata, whereas RdNBR, a variant of dNBR, estimates relative magnitude of change and potentially removes any bias of pre-fire vegetation conditions (Miller et al.
2009). Using RdNBR, for example, a stand-replacing fire in sparse shrub is rated as severely as one in dense forest (Miller and Thode 2007). Previous studies suggest that RdNBR has a stronger correlation with ground-collected metrics of burn severity (Eidenshink et al. 2007), especially forested settings and areas of high burn severity in relatively lower vegetation density settings. Beginning in 2007, the MTBS program began incorporating the standard RdNBR thresholds determined by Miller and Thode (2007) into the MTBS mapping workflow in order to provide a starting point for analysts to define burn severity thresholds (see Fig. 1 for an example of thematic burn severity classification).

At the inception of MTBS, it was anticipated that burn severity assessments would utilize imagery acquired at the peak-of-green during the growing season following a fire (i.e., an extended assessment). The intent of an extended assessment is to allow for delayed effects (mortality, survival, and recovery) to manifest on the landscape (Key 2005). Rapid regrowth of burned vegetation, however, made the exclusive use of extended assessments problematic in the southwestern and southeastern United States, and herbaceous areas throughout the CONUS. In the Southwest, fire effects that were easily observed in immediate post-fire imagery for low elevation fires (e.g., for the 26 May 2005 Duzak Fire in southern Nevada, USA) but disappeared by the next growing season because of rapidly regenerating herbaceous and shrub vegetation. This resulted in large areas that were characterized as "unburned to low" severity in an extended assessment, so an "initial assessment" became the preferred assessment strategy within areas of vegetation that rapidly regenerate.

Most fires in the Southeast occur in the late winter and early spring months and burned areas can green up within two to three months due to rapid regeneration of understory vegetation. Additionally, some areas in the Southeast exhibit low relief and poor drainage (e.g., wetlands), resulting in changing hydrologic conditions over the course of a year and between years (dry versus saturated soils). These areas frequently burn every two to four years and typically have relatively persistent cloud cover, which made the requirement for phenologically matching scene pairs difficult (Picotte and Robertson 2011a). After receiving critical feedback from Southeast resource managers and field assessments by MTBS staff, the MTBS assessment and mapping protocol for the Southeast was also modified to preferentially use an initial assessment within two months of fire start. Extended assessments are only performed if no suitable post-fire imagery is available. If no suitable pre-fire image is available, particularly in areas with inter-annual variability in hydrologic conditions, then a single-scene assessment is made using the post-fire imagery alone. 
Special accommodations to the mapping protocol were also necessary to assess some fires in Alaska. The Landsat scene acquisition footprints overlap significantly in higher latitudes (Bindschadler 2003), which allows an area to be imaged two to three times in the nominal 16-day Landsat orbit cycle. However, persistent cloud cover can negate this advantage and many fires were not imaged for an entire year. Also, there were substantial periods of time (years) when no Landsat data were acquired due to ground station problems (Goward et al. 2006). The availability of quality and comprehensive Landsat data was further impacted by the lost capacity of the Landsat TM to temporarily store collected imagery on board and the preferences of ground stations in Canada and Alaska to acquire Landsat ETM+ over TM. If MTBS had strictly adhered to the one-year post-fire scene acquisition, many Alaska fires would not have been assessed by the program. In these cases, post-fire Landsat imagery acquired more than one year after the fire with no other significant land cover disturbances were used. Vegetation recovery in boreal forests can be slower than in forests at more southern latitudes (White et al. 2017; e.g., Alaska versus CONUS), which alleviates the need for rapid post-fire image acquisition.

Costs for imagery acquisition also had an important impact on the MTBS program. Before 2008, when the Landsat image archive became publicly and freely available, MTBS had to purchase Landsat imagery, which generally limited the project to two Landsat images per year for most Worldwide Reference System-2 (WRS-2) Path/Rows, unless additional scenes were acquired previously by federal partners in the Multi-Resolution Land Cover (MRLC) consortium. This cost-related restriction limited the ability of analysts to select the best available image for each fire assessment, resulting in potential burned area boundary and burn severity product errors as well as unmappable fires. In 2008, the Landsat archive was opened for free distribution of data (Wulder et al. 2012), which allowed for the reassessment of previously image-limited and unmappable fires. The MTBS recently completed revisiting 5012 fire records that were declared unmappable in the first few years of the program and was able to map 2248 of these fires. Meanwhile, the program revisited the largest fires that had been mapped spanning the period from 1984 to 2007 to determine if the best available imagery was used. Fires ranging from 2000 to 20000 hectares were evaluated for their prescribed assessment strategy, errors in area burned, consistency in dNBR offsets (average dNBR value of unburned areas outside the burned area), applied burn severity thresholds, availability of quality pre- and post-fire imagery, and the phenological compatibility of selected imagery. When issues were identified for one or more of these evaluation criteria, fires were remapped using imagery previously not available because of costs and program budget constraints. Additionally, over 6000 occurrence records for relatively smaller fires were declared unmappable in the first few years of the MTBS program due to limits on imagery procurement. The MTBS program is currently revisiting these fires to determine if suitable imagery is now available to support their assessment, and mapping and will continue to revisit smaller fires from 1984 to 2008 as time and funding allow.

\section{MTBS data caveats and limitations}

The purpose of the MTBS burned area mapping product is to provide an estimate of the area that may have been affected by fire. This liberal approach to mapping burned areas leads to the potential for incorrect inclusion of unburned areas (i.e., errors of commission). Indeed, at the onset of the MTBS program, Kolden and Weisberg (2007) identified potential problems with commission error (mean commission error $=18 \%$ ) when using Landsat data to map burned area boundaries in Nevada. Picotte and Robertson (2010) found similar commission errors in the southeastern United States (mean commission error $=15 \%)$. Incorrect exclusion of pixels (i.e., omission error) is also possible and was estimated to range between $0 \%$ and $45 \%$ by Kolden and Weisberg (2007). Errors in estimating burned area from Landsat data can result from the amount of time between when the area burned and image acquisition (Picotte and Robertson 2010; Picotte and Robertson 2011a), terrain complexity (Kolden and Weisberg 2007), and vegetation composition (Vanderhoof et al. 2017). Although MTBS attempts to obtain the best available preand post-fire Landsat images for burned area mapping, commission errors in the burned area extent can be problematic as a result of inherent problems with Landsat data quality and availability, and because MTBS does not remove unburned islands from within the burned area boundary (Eidenshink et al. 2007). MTBS product commission errors have been estimated to be $46.4 \%$ in the US Pacific Northwest (Meddens et al. 2016) and to range between $4.3 \%$ to $15.5 \%$ in the northern US Great Basin (Sparks et al. 2015). Burned area extent commission error could be mitigated by removing unburned areas as identified in the MTBS thematic burn severity product (Kolden et al. 2015), although this could result in the incorrect removal of low severity pixels, resulting in omission error.

Kolden et al. (2015) also identified three potential problems with the MTBS thematic burn severity production: the dNBR offset (phenology difference) is not applied in producing thematic severity data, burn thresholds are variable and subjectively determined, and burn 
severity thresholds are not tied to a quantifiable ecological measure (i.e., field validated). The dNBR offset, the mean value of unburned pixels near the fire boundary that occur within the same vegetation type (i.e., evergreen forests) as most-burned pixels, is currently calculated for each fire mapped by MTBS and is contained within the metadata for each MTBS fire. This offset could be applied (i.e., subtracted) from every dNBR image and from the burn severity thresholds to remove the phenological differences to potentially create more universally comparable burn severity estimates across time. Deriving dNBR offsets can be a subjective process. Consequently, applying the dNBR offset does not actually change the classified burn severity image. Offsets also do not mitigate the subjectivity of the burn severity thresholds but may correct the thresholds to make them potentially comparable between fires. Comparisons between analyst-selected thresholds and an automated Otsu (Otsu 1979) spectral thresholding procedure for 18 497 MTBS fires mapped between 1984 and 2014 suggest that the low, moderate, and high severity class breakpoints could be highly variable, although low severity breakpoints were similar (Picotte 2019). The MTBS program applies measures to ensure consistency among analysts in determining burn severity thresholds. Burn severity thresholds are consistently reviewed before release and analysts examine both classified vegetation products and high-resolution imagery to examine where low, moderate, and high burn severity breakpoints are occurring. There is also currently an effort to visually review all fires to ensure that visually determined burn severity thresholds occur with appropriate vegetation (e.g., no high severity in grasslands) and are near dNBR ranges suggested by Key and Benson (2006). None of these remote sensing efforts directly measure the ecological effects of burn severity, primarily because spatially and temporally comprehensive field data are not available for most fires throughout the MTBS data record. However, recent work does suggest that MTBS severity classifications can be associated with tree mortality (Meigs et al. 2011) or vegetation regrowth after fires (Johnston et al. 2019). Additionally, the program plans to leverage the increasing availability of CBI data (see Picotte et al. 2019 for dataset) to better calibrate remotely sensed MTBS burn severity estimates to ground conditions (see Fig. 1 for example $\mathrm{CBI}$ and dNBR values stratified by thematic classification). Regression relationships between $\mathrm{CBI}$ and $\mathrm{dNBR}$ and NBR could be developed to allow for automatic conversion of MTBS dNBR and NBR products to CBI estimates of burn severity. A similar approach using Random Forests (Pal 2005) to convert dNBR and NBR to CBI has already been developed by Parks et al. (2019).

\section{Examination of changes to MTBS data}

The MTBS program reviewed all fires that were $\geq 2023$ hectares $(n=6588)$. Of these reviewed fires, 794 were identified as potentially having imagery or mapping errors. A total of 123 fires subsequently were remapped because of potential issues (Fig. 2), including detectable errors in burned area boundary delineation, over- or underestimation of incorrect burn severity classes due to selected thresholds, phenological mismatch of selected pre- and post-fire imagery, image quality for one or both images, and excess unburned area within the burned area boundary. Errors were grouped into two remap categories: (1) image change: the actual burned area boundary did not change, but the underlying Landsat imagery of the mapped fire was changed because of pre- and post-fire image pairing, burn severity class thresholds, or image quality; and (2) burned area boundary: the burned area boundary was altered, although the underlying imagery may also have changed because of an incorrect burned area boundary, excess burned area was delineated, or altered burn severity class thresholds.

Overall metrics that calculated the number of remapped fires were examined by both fire year and state. Each original and remapped fire was separately examined for significant changes within the burned area and the number of pixels in unburned, low, moderate, and high burn severity categories. Because the distribution of each of the burned area boundary and pixel counts per burn severity classification was nonparametric, Wilcoxon signed-rank tests (Wilcoxon 1945) were used to test for differences between the datasets. To determine whether differences were both numeric and spatial, the amount of spatial overlap (i.e., percentage overlap) between burned area boundary and categorized thresholded pixels was also calculated.

Results from the fire analysis illustrated that fires were more likely to be remapped because of burned area boundary changes rather than image changes (Fig. 3a.). Most fires (69\%) were remapped after 1996 (midway in remapped fire history; Fig. 3b). Compared to the overall average of five fires remapped per year between 1984 and 2003, the average number of fires remapped increased to eight fires per year between 2004 and 2007. Overall, there was a slight positive trend $\left(R^{2}=0.30\right)$ in the number of remapped fires increasing over time.

When examining geographic trends in fire revision number, it was evident that most revised fires were in the western CONUS (Fig. 3c). California, Montana, Idaho, Oregon, New Mexico, and Nevada had at least ten fires remapped and accounted for 59\% of all remapped fires. Only three fires within the eastern CONUS were remapped, and these were within Louisiana and Florida. 

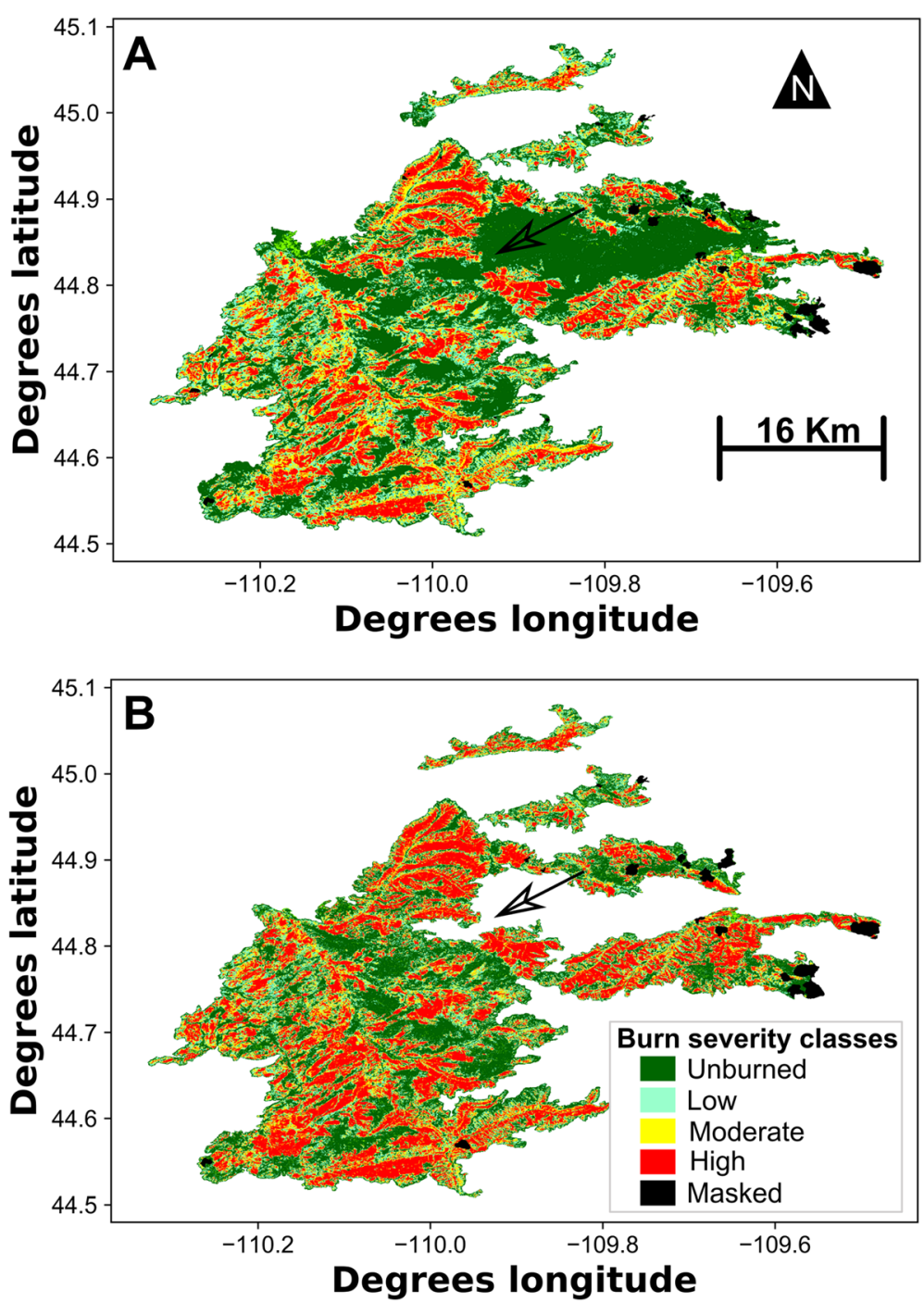

Fig. 2 Example of the visual difference (indicated by an arrow) for (A) the original versus (B) the remapped 11 July 1988 Clover Mist Fire in Yellowstone National Park, USA, mapped by the Monitoring Trends in Burn Severity (MTBS) program

Overall, although many burned area boundaries were changed (Fig. 3a), there was not a significant difference in burned area between the original and remapped fires (Table 1). The number of burn severity pixels for each burn severity threshold class, however, did vary significantly (Table 1). There was a large degree of spatial overlap between original and remapped high severity pixels. All other burn severity classes exhibited lower values of percent overlap, although all were above $50 \%$.

\section{Discussion}

During the past 14 years, the MTBS program has mapped burned area boundaries and burn severity for 22960 fires across the United States. Changes to the MTBS mapping procedures and in Landsat data availability have resulted in potentially disparate burned area boundaries and severity products. MTBS data users should be aware that changes implemented by the program can be significant, especially on a per fire basis.

\section{Burned area boundary and burn severity change}

Following the increases in fire occurrence and burned area across much of the CONUS (see Dennison et al. 2014 and Picotte et al. 2016 for fire occurrence and area trends), the number of reported fires and burned area mapped by MTBS has increased over time (Finco et al. 2012). The slight increase in the number of fires remapped by MTBS also likely mirrors these trends. A smaller potential influence on the increased 

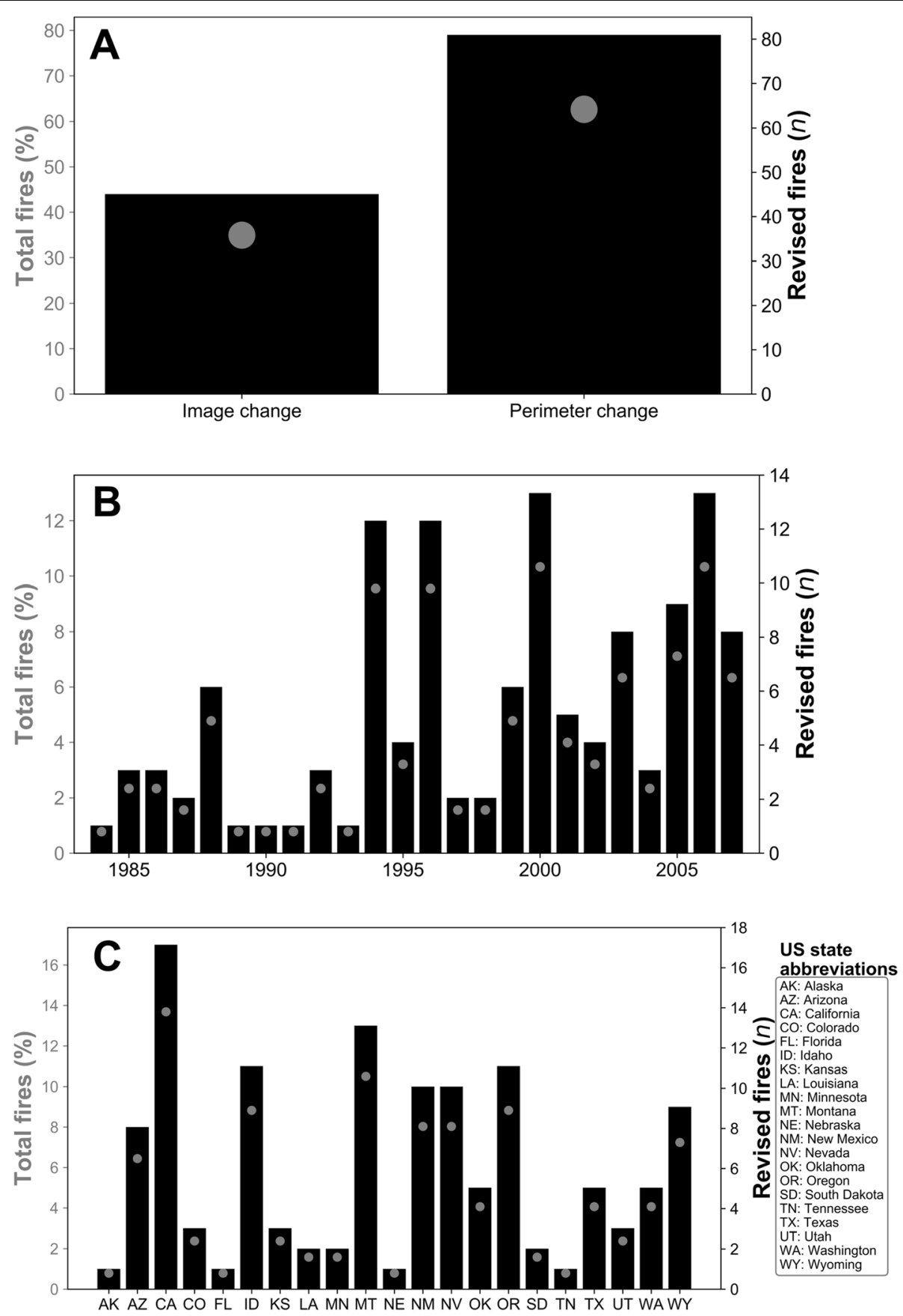

Fig. 3 Histograms of Monitoring Trends in Burn Severity percent of total fires (left $y$-axis; gray dots) and number of revised fires (right $y$-axis; black bars) subdivided by $(\mathbf{A})$ reason for revision, (B) year, and (C) US state

number of fires that were remapped is the Landsat ETM+ scan line corrector failure in 2003 (Storey et al. 2005), after which the average number of fires remapped notably increased. Landsat ETM+ with scan line issues would have been used preferentially to TM images if a greater number of fires could be mapped with the ETM+ imagery or if the TM image was largely cloud contaminated. Using ETM+ data would have resulted in data gaps within some mapped burned area boundaries. Once Landsat images were made freely available in 2008, a subsequent review of the fire mappings resulted in the remapping of fires using Landsat TM imagery to reduce the amount of per-fire data gaps. 
Table 1 Difference in burned area (hectares) and number (n) of classified unburned, low, moderate, and high burn severity pixels for the original versus the revised Monitoring Trends in Burn Severity (MTBS) program's burned area and burn severity products. The percentage of overlapping area or classified burn severity pixels (Mean overlap \%), difference in area or number of pixels (Median difference), and the Wilcoxon signed rank test $P$-value indicates whether there was a significant difference between the original versus revised MTBS area or burn severity products. Standard deviation (SD) was also calculated for mean overlap and median difference

\begin{tabular}{lrrr}
\hline & \multicolumn{3}{c}{ Difference between original versus revised MTBS program output } \\
\cline { 2 - 5 } & Mean overlap \% (SD) & Median difference (SD) & 0 (2 554) \\
\hline Burned area (hectares) & $93(19)$ & $-1608(22709)$ & $<.969$ \\
Unburned severity pixels $(n)$ & $69(21)$ & $5848(10369)$ & $<0.001$ \\
Low severity pixels $(n)$ & $54(24)$ & $-2(8224)$ & $<0.001$ \\
Moderate severity pixels $(n)$ & $57(23)$ & $-275(11898)$ & $<.045$ \\
High severity pixels $(n)$ & $82(22)$ & & $<0.001$ \\
\hline
\end{tabular}

Geographically, it was expected that the number of fires remapped was weighted toward the western United States, given that area burned is generally greater in the western versus the eastern US (Hoover and Hanson 2019). Additionally, there are fewer fires $\geq 2023$ hectares in the eastern United States. However, given that more than $35 \%$ of the fires in the MTBS archive are eastern US fires, it is surprising that only three would be remapped. This paucity of eastern US remapped fires could have resulted from the decreased availability of quality Landsat imagery during certain parts of the year and because of the rapid regeneration of vegetation in the eastern United States (Picotte and Robertson 2011a), resulting in the use of NBR imagery preferentially to dNBR.

The majority of MTBS fires that were remapped resulted in a change in the burned area boundary. Although there was a change in area, these current revisions of MTBS burned area boundary data have not significantly impacted the area of most revised fires. This is good, given that previous research has been undertaken that examines burned area trends using MTBS data (Finco et al. 2012; Dennison et al. 2014; Zhao et al. 2015; Picotte et al. 2016). Time series trend analyses using Mann-Kendall and Spearman's rho tests (e.g., as used in Dennison et al. 2014; Picotte et al. 2016) are sensitive to sample size and data distribution (Yue et al. 2002). A relatively small number of large changes in assessed burned area could therefore result in disappearance of some trends in burned area, especially if the burned area sample size was small. It is possible that studies that examine a small number of MTBS mapped burned area boundaries (e.g., Sparks et al. 2015) could be impacted if the fires that were remapped were significantly altered.

Most fires for which there was a burned area boundary change also underwent imagery changes. Unlike burned area boundary changes, the number of pixels by threshold class within the remapped MTBS thresholded burn product is significantly different from original mappings. These burn severity changes could alter the results of studies using classified severity product (e.g., Meigs et al. 2011; Finco et al. 2012; Zhao et al. 2015), especially if individual fires under examination were remapped (e.g., Pierce et al. 2012). Even studies that did not use the classified severity product (e.g., Picotte et al. 2016), but used the continuous dNBR, NBR, or RdNBR products, could be affected. These potential problems are somewhat tempered by the fact that over $50 \%$ of severity pixels per class for the remapped fires still overlapped the same severity classes in the original imagery, and the high severity class exhibited $80 \%$ overlap. This suggests that, even though different Landsat scenes were used for the remapped fires, new scenes were not always significantly different in terms of MTBS classified estimates of burn severity.

\section{MTBS program future plans}

The MTBS program will continue to integrate new Landsat datasets as they become available (e.g., Landsat 9 mission). Additionally, as new sensors become available (e.g., Sentinel 1 and 2), the MTBS will use these new data sources if they are spectrally similar and have as good or better resolution. The overall idea is to continuously improve the quality and integrity of MTBS data products while reducing frequency of unmappable fires.

Beginning with the 2018 fire year, the MTBS program began to adapt and use Sentinel 2 Multispectral Instrument (MSI) imagery, developed and provided by the European Space Agency. Sentinel MSI data are available from two Sentinel 2 platforms (Sentinel 2A and Sentinel 2B) and have the potential to complement the use of Landsat data in the MTBS program because of Sentinel MSI's near- and mid-infrared band similarity, comparable spatial resolution, and a much shorter revisit time due to the concurrent availability of MSI sensors on two platforms and a larger swath compared to Landsat (Wang et al. 2017). Previous studies have found Sentinel 
MSI to be a reasonable sensor for mapping burned area boundaries (Filipponi 2019; Roteta et al. 2019) and burn severity (Lasaponara et al. 2018). Because of the differences in Landsat and Sentinel resolution and spectral bands, some technical adaptations are needed to integrate both sensors (Wang et al. 2017) in order to calculate reasonably consistent pre- and post-fire NBR and, subsequently, dNBR and RdNBR. Once this integration has been completed, MTBS analysts will use Landsat, or Sentinel 2 data as needed, to map burned area boundaries and burn severity. Pairing the use of Sentinel 2 imagery with Landsat (i.e., mapping fires with Sentinelonly, Landsat-only, or Sentinel and Landsat together) will significantly increase the observation frequency of burned areas and result in a higher availability of quality imagery and better phenologically matched image pairs for fire mapping.

During the lifetime of the MTBS program, MTBS analysts have selectively mapped additional fires at the request of federal partners with their financial support. For example, MTBS has routinely conducted initial assessments of burn severity for prescribed fires on National Park Service units throughout the CONUS. Additionally, MTBS has partnered with the US Fish and Wildlife Service to map burned area boundaries for fires on selected refuges. Fire geospatial products produced through these partnerships may not include the full suite of MTBS fire products for each fire, follow best practices for pre- and postfire image pairing, or meet MTBS's burned area size criteria. Consequently, these products are not currently distributed to the public. However, in the future, MTBS plans to distribute these additional fire geospatial data as a courtesy to the user community through a new web-based data distribution system in fall 2020. These data will be provided distinctly separate from MTBS data and users should be aware of what is provided with these data and their limitations and understand that they are not considered to be official MTBS data records.

\section{Conclusions}

This paper endeavors to inform users about changes to the MTBS fire mapping protocols and data sources used. The MTBS dataset is dynamic and will improve as problems are identified or new data become available. Users should also be aware of continuing updates to MTBS products in the MTBS archive; currently there are 22969 mapped fires available, and users should always download the most recent individual fire datasets or mosaics to ensure that they are using the most up-to-date burned area boundary products. Although not examined in this study, there will be an additional 1000 or more previously found or previously unmappable (due to lack of image availability at the beginning of the MTBS program) fires added to the MTBS archive. We envision that the MTBS data archive will continue to increase in utilization because of these changes.

\section{Acknowledgements \\ Special thanks to S. Howard (USGS, retired) for initiating the effort on this paper, C. Deering (KBRwyle) for performing the literature searches documented within this paper, and T. Hawbaker (USGS) for internal review of this paper. Any use of trade, firm, or product names is for descriptive purposes only and does not imply endorsement by the US government.}

\section{Authors' contributions}

$J J P, K B, D H, J L, J E, B Q, N B$, and $K N$ conceived this study. JJP, $K B$, and JL performed the data analyses. JJP, KB, DH, JL, JE, BQ, NB, and $K N$ all contributed writing for this manuscript and approved the submitted manuscript.

\section{Funding}

This study was supported by the MTBS program. ASRC Federal Data Solutions contractor work was performed under USGS contract 140G0119C0001. KBRwyle contractor work was performed under USGS contract G15PC00012. RedCastle Resources contractor work was performed under USDA Forest Service contract 1284JC18D0005.

\section{Availability of data and materials}

Data available at https://mtbs.gov/

Ethics approval and consent to participate Not applicable.

\section{Consent for publication}

Not applicable.

\section{Competing interests}

The authors declare no competing interests.

\section{Author details}

${ }^{1}$ ASRC Federal Data Solutions, Contractor to the US Geological Survey, Earth Resources Observation and Science Center, 47914 252nd Street, Sioux Falls, South Dakota 57198, USA. ${ }^{2}$ KBRwyle, Contractor to the US Geological Survey, Earth Resources Observation and Science Center, 47914 252nd Street, Sioux Falls, South Dakota 57198, USA. ${ }^{3}$ RedCastle Resources, Contractor to US Department of Agriculture Forest Service, Geospatial Technology and Applications Center, 125 S State Street, Suite 7105, Salt Lake City, Utah 84138, USA. ${ }^{4}$ US Department of Agriculture Forest Service, Geospatial Technology and Applications Center, 125 S State Street, Suite 7105, Salt Lake City, Utah 84138, USA. ${ }^{5}$ National Park Service, Fire Management Program Center, 3833 Development Avenue, Boise, Idaho 83705, USA. ${ }^{6}$ US Geological Survey, Earth Resources Observation and Science Center, 47914 252nd Street, Sioux Falls, South Dakota 57198, USA.

Received: 18 December 2019 Accepted: 27 May 2020

Published online: 25 June 2020

\section{References}

Bindschadler, R. 2003. Landsat coverage of the earth at high latitudes. Photogrammetric Engineering \& Remote Sensing 69: 1333-1339. https://doi. org/10.14358/PERS.69.12.1333

Cansler, C.A., and D. McKenzie. 2012. How robust are burn severity indices when applied in a new region? Evaluation of alternate field-based and remotesensing methods. Remote Sensing 4: 456-483. https://doi.org/10.3390/ rs4020456.

Dennison, P.E., S.C. Brewer, J.D. Arnold, and M.A. Moritz. 2014. Large wildfire trends in the western United States, 1984-2011. Geophysical Research Letters 41: 2928-2933. https://doi.org/10.1002/2014GL059576. 
Eidenshink, J., B. Schwind, K. Brewer, Z. Zhu, B. Quayle, and S. Howard. 2007. A project for monitoring trends in burn severity. Fire Ecology 3: 3-21. https:// doi.org/10.4996/fireecology.0301003.

Filipponi, F. 2019. Exploitation of Sentinel-2 Time Series to Map Burned Areas at the National Level: A Case Study on the 2017 Italy Wildfires. Remote Sensing 11: 622. https://doi.org/10.3390/rs11060622

Finco, M., B. Quayle, Y. Zhang, J. Lecker, KA. Megown, and C.K. Brewer. 2012. Monitoring Trends and Burn Severity (MTBS): monitoring wildfire activity for the past quarter century using Landsat data. In Proceedings: Moving from Status to Trends: Forest Inventory and Analysis (FIA) Symposium; 2012 December 4-6; Baltimore, MD, ed. R. Morin and G. Liknes, 222-228. Newtown Square: U.S. Department of Agriculture, Forest Service, Northern Research Station.

French, N.H., D. McKenzie, T. Erickson, B. Koziol, M. Billmire, K.A. Endsley, N.K. Yager Scheinerman, L. Jenkins, M.E. Miller, and R. Ottmar. 2014. Modeling regionalscale wildland fire emissions with the Wildland Fire Emissions Information System. Earth Interactions 18: 1-26. https://doi.org/10.1175/El-D-14-0002.1.

García, M.L., and V. Caselles. 1991. Mapping burns and natural reforestation using Thematic Mapper data. Geocarto International 6: 31-37. https://doi.org/10. 1080/10106049109354290

Goward, S., T. Arvidson, D. Williams, J. Faundeen, J. Irons, and S. Franks. 2006. Historical record of Landsat global coverage. Photogrammetric Engineering \& Remote Sensing 72: 1155-1169. https://doi.org/10.14358/PERS.72.10.1155.

Hoover, K., and L. Hanson. 2019. Wildfire Statistics, 2. Washington D.C. Congressional Research Service.

Johnston, J.D., C.J. Dunn, and M.J. Vernon. 2019. Tree traits influence response to fire severity in the western Oregon Cascades, USA. Forest Ecology and Management 433: 690-698. https://doi.org/10.1016/j.foreco.2018.11.047.

Key, C.H. 2005. Remote sensing sensitivity to fire severity and fire recovery. In Proceedings of the 5 th international workshop on remote sensing and GIS applications to forest fire management: fire effects assessment, ed. J. De la Riva, F. Perez-Cabello, and E. Chuvieco, 29-39. Spain: Universidad de Zaraoza.

Key, C.H., and N.C. Benson. 2006. Landscape assessment (LA): sampling and assessment methods. In FIREMON: Fire effects monitoring and inventory system, 1-55. Fort Collins: U.S. Department of Agriculture, Forest Service, Rocky Mountain Research Station.

Kolden, C.A., A.M. Smith, and J.T. Abatzoglou. 2015. Limitations and utilisation of Monitoring Trends in Burn Severity products for assessing wildfire severity in the USA. International Journal of Wildland Fire 24: 1023-1028. https://doi.org/ 10.1071/WF15082.

Kolden, C.A., and P.J. Weisberg. 2007. Assessing accuracy of manually-mapped wildfire perimeters in topographically dissected areas. Fire Ecology 3: 22-31. https://doi.org/10.4996/fireecology.0301022.

Lasaponara, R., B. Tucci, and L. Ghermandi. 2018. On the Use of Satellite Sentinel 2 Data for Automatic Mapping of Burnt Areas and Burn Severity. Sustainability 10: 3889. https://doi.org/10.3390/su10113889.

Meddens, A.J., C.A. Kolden, and J.A. Lutz. 2016. Detecting unburned areas within wildfire perimeters using Landsat and ancillary data across the northwestern United States. Remote Sensing of Environment 186: 275-285. https://doi.org/ 10.1016/j.rse.2016.08.023.

Meigs, G.W., D.P. Turner, W.D. Ritts, Z. Yang, and B.E. Law. 2011. Landscape-scale simulation of heterogeneous fire effects on pyrogenic carbon emissions, tree mortality, and net ecosystem production. Ecosystems 14: 758-775. https://doi. org/10.1007/s10021-011-9444-8.

Meigs, G.W., H.S. Zald, J.L. Campbell, W.S. Keeton, and R.E. Kennedy. 2016. Do insect outbreaks reduce the severity of subsequent forest fires? Environmental Research Letters 11: 045008. https://doi.org/10.1088/1748-9326/ 11/4/045008

Miller, J.D., and A.E. Thode. 2007. Quantifying burn severity in a heterogeneous landscape with a relative version of the delta Normalized Burn Ratio (dNBR). Remote Sensing of Environment 109: 66-88. https://doi.org/10.1016/j.rse.2006.12.006.

Miller, J. D., Knapp, E. E., Key, C. H., Skinner, C. N., Isbell, C. J., Creasy, R. M., \& Sherlock, J. W. 2009. Calibration and validation of the relative differenced Normalized Burn Ratio (RdNBR) to three measures of fire severity in the Sierra Nevada and Klamath Mountains, California, USA. Remote Sensing of Environment, 113(3), 645-656.

Otsu, N. 1979. A threshold selection method from gray-level histograms. IEEE Transactions on Systems, Man, and Cybernetics 9: 62-66. https://doi.org/10. 1109/TSMC.1979.4310076.

Pal, M. 2005. Random forest classifier for remote sensing classification. International Journal of Remote Sensing 26 (1): 217-222. https://doi.org/10. 1080/01431160412331269698.
Parks, S.A., L.M. Holsinger, MJ. Koontz, L. Collins, E. Whitman, M.-A. Parisien, R.A. Loehman, J.L. Barnes, J.-F. Bourdon, and J. Boucher. 2019. Giving ecological meaning to satellite-derived fire severity metrics across North American forests. Remote Sensing 11: 1735. https://doi.org/10.3390/rs11141735.

Picotte, J.J. 2019. Development of a new open-source tool to map burned area and burn severity. In Proceedings of the Fire Continuum Conference, 1-18.

Picotte, J.J., R.S. Arkle, H. Bastian, N. Benson, C.A. Cansler, T. Caprio, G.K. Dillon, C.H. Key, R.N. Klein, K. Kopper, A.J. Meddens, D. Ohlen, S.A. Parks, D.W. Peterson, D.S. Pilliod, S. Pritchard, K. Robertson, A.M. Sparks, and A. Thode. 2019. Composite Burn Index (CBI) Data for the Conterminous US, Collected Between 1996 and 2018. In U.S.G.S.d. release https://www.sciencebase.gov/ catalog/item/5d963705e4b0c4f70d110ee6.

Picotte, J.J., B. Peterson, G. Meier, and S.M. Howard. 2016. 1984-2010 trends in fire burn severity and area for the conterminous US. International Journal of Wildland Fire 25: 413-420. https://doi.org/10.1071/WF15039.

Picotte, J.J., and K. Robertson. 2011a. Timing constraints on remote sensing of wildland fire burned area in the southeastern US. Remote Sensing 3: 16801690. https://doi.org/10.3390/rs3081680.

Picotte, J.J., and K.M. Robertson. 2010. Accuracy of remote sensing wildland fireburned area in southeastern U.S. Coastal Plain habitats. In Proceedings of the 24th Tall Timbers Fire Ecology Conference: The Future of Prescribed Fire: Public Awareness, Health, and Safety, ed. K.M. Robertson, K.E.M. Galley, and R.E. Masters, 86-93. Tallahassee: Tall Timbers Research Station.

Picotte, J.J., and K.M. Robertson. 2011 b. Validation of remote sensing of burn severity in south-eastern US ecosystems. International Journal of Wildland Fire 20: 453-464. https://doi.org/10.1071/WF10013.

Pierce, A.D., C.A. Farris, and A.H. Taylor. 2012. Use of random forests for modeling and mapping forest canopy fuels for fire behavior analysis in Lassen Volcanic National Park, California, USA. Forest Ecology and Management 279: 77-89. https://doi.org/10.1016/j.foreco.2012.05.010.

Radeloff, V.C., D.P. Helmers, H.A. Kramer, M.H. Mockrin, P.M. Alexandre, A. Bar-Massada, V. Butsic, T.J. Hawbaker, S. Martinuzzi, and A.D. Syphard. 2018. Rapid growth of the US wildland-urban interface raises wildfire risk. Proceedings of the National Academy of Sciences 115: 3314-3319. https://doi.org/10.1073/pnas.1718850115.

Roteta, E., A. Bastarrika, M. Padilla, T. Storm, and E. Chuvieco. 2019. Development of a Sentinel-2 burned area algorithm: Generation of a small fire database for sub-Saharan Africa. Remote Sensing of Environment 222: 1-17. https://doi.org/ 10.1016/j.rse.2018.12.011.

Short, K. 2014. A spatial database of wildfires in the United States, 1992-2011. Earth System Science Data 6: 1-27. https://doi.org/10.5194/essd-6-1-2014.

Short, K.C. 2015. Sources and implications of bias and uncertainty in a century of US wildfire activity data. International Journal of Wildland Fire 24: 883-891. https://doi.org/10.1071/WF14190.

Sparks, A.M., L. Boschetti, A.M. Smith, W.T. Tinkham, K.O. Lannom, and B.A. Newingham. 2015. An accuracy assessment of the MTBS burned area product for shrub-steppe fires in the northern Great Basin, United States. International Journal of Wildland Fire 24: 70-78. https://doi.org/10.1071/WF14131.

Storey J.C., Scaramuzza P., Schmidt G. Landsat 7 scan line corrector-off gap filled product development. PECORA 16 Conference Proceedings, Sioux Falls, South Dakota, pp. 23-27

Urbanski, S., W. Hao, and B. Nordgren. 2011. The wildland fire emission inventory: western United States emission estimates and an evaluation of uncertainty. Atmospheric Chemistry and Physics 11: 12973-13000. https:/doi.org/10.5194/acp-11-12973-2011.

Vanderhoof, M.K., N. Fairaux, Y.-J.G. Beal, and T.J. Hawbaker. 2017. Validation of the USGS Landsat burned area essential climate variable (BAECV) across the conterminous United States. Remote Sensing of Environment 198: 393-406. https://doi.org/10.1016/j.rse.2017.06.025.

Wang, Q., G.A. Blackburn, A.O. Onojeghuo, J. Dash, L. Zhou, Y. Zhang, and P.M. Atkinson. 2017. Fusion of Landsat 8 OLI and Sentinel-2 MSI data. IEEE Transactions on Geoscience and Remote Sensing 55: 3885-3899. https://doi. org/10.1109/TGRS.2017.2683444.

White, J.C., M.A. Wulder, T. Hermosilla, N.C. Coops, and G.W. Hobart. 2017. A nationwide annual characterization of 25 years of forest disturbance and recovery for Canada using Landsat time series. Remote Sensing of Environment 194: 303-321. https://doi.org/10.1016/j.rse.2017.03.035.

Wilcoxon, F. 1945. Individual Comparisons by Ranking Methods. Biometrics Bulletin 1 (6): 80-83. https://doi.org/10.2307/3001968.

Wulder, M.A., J.G. Masek, W.B. Cohen, T.R. Loveland, and C.E. Woodcock. 2012. Opening the archive: How free data has enabled the science and monitoring 
promise of Landsat. Remote Sensing of Environment 122: 2-10. https://doi. org/10.1016/.j.re.2012.01.010.

Yue, S., P. Pilon, and G. Cavadias. 2002. Power of the Mann-Kendall and Spearman's rho tests for detecting monotonic trends in hydrological series. Journal of Hydrology 259: 254-271. https://doi.org/10.1016/S0022-1694(01)00594-7.

Zhao, F., R. Keane, Z. Zhu, and C. Huang. 2015. Comparing historical and current wildfire regimes in the Northern Rocky Mountains using a landscape succession model. Forest Ecology and Management 343: 9-21. https:/doi.org/ 10.1016/j.foreco.2015.01.020

Zhu, Z., C.H. Key, D. Ohlen, and N.C. Benson. 2006. Evaluate sensitivies of burnseverity mapping algorithms for different ecosystems and fire histories in the United States, 1-36. Sioux Falls: U.S. Department of Interior.

\section{Publisher's Note}

Springer Nature remains neutral with regard to jurisdictional claims in published maps and institutional affiliations.

\section{Submit your manuscript to a SpringerOpen ${ }^{\circ}$ journal and benefit from:}

- Convenient online submission

- Rigorous peer review

- Open access: articles freely available online

- High visibility within the field

- Retaining the copyright to your article

Submit your next manuscript at $\boldsymbol{\wedge}$ springeropen.com 